\title{
DOS COLGANTES EXCEPCIONALES DEL MUSEO ARQUEOLOGICO DE IBIZA
}

\author{
Maria Pilar San Nicolas Pedraz
}

Con estas dos piezas que presentamos, dos colgantes ebusitanos de plata, queremos rendir justo homenaje al que fue nuestro ilustre Profesor, Dr. D. G. Nieto y Gallo (1). Fueron halladas en la necrópolis del Puig des Molins, la primera en 1946 por J. M. Mañá de Angulo, pero no fue dada a conocer hasta 1984 por C. Gómez Bellard (2); la segunda, inédita hasta la fecha, apareció en la campaña de 1985 en el Solar de Can Partit, dirigida por B. Costa (3). Ambos colgantes se encuentran depositados en el Museo Arqueológico de Ibiza.

\section{Estudio de las piezas}

\section{1. ${ }^{\circ} \quad$ N. INV.: MAI 7259 (fig. 1).}

Colgante de forma circular, con umbo central y sistema de suspensión en forma de carrete estriado, formado por un cilindro de hilo enrollado, rematado por un ribete de hilo liso. Recorre su contorno un ribete semicircular que penetra hacia el interior en su parte inferior. Reverso liso.

Alt. 2,2 cm. D. disco: entre 1,7 y $1,9 \mathrm{~cm}$.

Buen estado de conservación (4).

Circunstancias del descubrimiento. Hallado en el hipogeo 30 de las excavaciones de Mañá de Angulo en 1946 en el Puig des Molins, Sector 2 al noroeste de la casa de Can Partit. Según su excavador, esta sepultura estaba totalmente vacía; sin embargo, C. Gómez Bellard, entre los dibujos y fotografías del diario de excavación,

(1) Los dibujos de las piezas están realizados por D. Delfín Salas Carmena, que ha querido adherirse con ellos al presente homenaje.

(2) Gómez Bellard, C.: La Necrópolis del Puig des Molins (Ibiza) Campaña de 1946, E.A.E. 132, Madrid, 1984, pág. 91, fig. 37,2, lám. VI, 4.

(3) Agradezco a D. B. Costa y a todos los colegas, que integran el dinámico equipo arqueológico del Museo de Ibiza el envío de datos y fotografías de esta nueva pieza, así como la autorización para su estudio a la espera de que pronto se publique la Memoria de esta campaña de excavación.

(4) Recientemente ha sido tratada en el Instituto de Restauración y Conservación, de Madrid. 

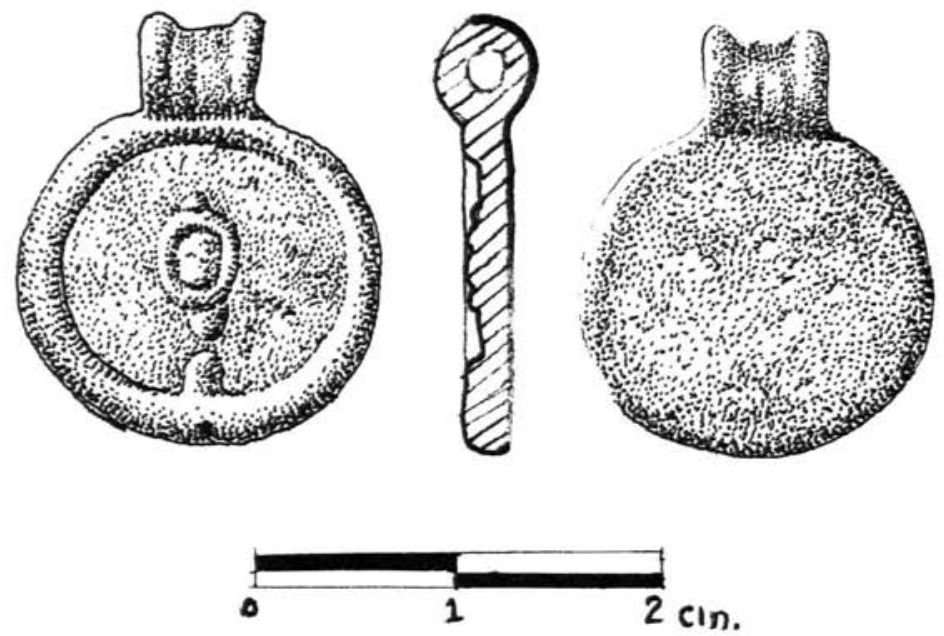

encontró el colgante y la parte superior de una jarra de dos asas y boca circular de la forma Eb. 64, como pertenecientes a este hipogeo (5).

Paralelos. La forma circular del medallón es conocida en todo el mundo oriental desde el II milenio, existiendo dos vertientes de difusión; por una parte, de Siria hacia Asia Menor; y por otra, hacia Italia y la cuenca occidental del Mediterráneo por Chipre y Rodas (6).

Este ejemplar ebusitano se incluye dentro del tipo Xc de Quattrocchi (7) y en las piezas denominadas por B. Quillard "colgantes circulares con umbo y contorno de junco con remate entrante" (8), documentadas ampliamente con ejemplares de oro, plata y plata dorada en todo el área fenicia-púnica del Mediterráneo Occidental, Cerdeña (Tharros). Sicilia (Motya), Norte de Africa (Cartago, Kouass, Rachgoun) y Península Ibérica (Jardín, Málaga y un ejemplar de procedencia desconocida que se conserva en el Museo Arqueológico Nacional de Madrid), fechados desde la segunda mitad del siglo VII ó VI a. C. Concretamente de Douîmes (Cartago), procede el ejemplar más famoso, hallado por Delattre en 1894, en el que figura la inscripción de Jadamelk solicitando a Pigmalión y Astarté que le protejan (9). Por lo tanto, es evidente la función de este objeto como amuleto protector contra los malos espíritus, a la vez que se le podría añadir un poder propiciatorio para atraer la buena suerte.

(5) Gómez Bellard, C.: Op. cit., págs. 90-91, figs. 36 y 37, 1.

(6) Quillard, B.: Bijoux carthaginois I. Les colliers. Louvain-La Neuve, 1979, pág. 79, notas 391-400.

(7) Quattrocchi Pisano, G.: I Gioielli fenici di Tharros nel Museo Nazionale di Cagliari, (Coll. Studi Fenici, 3), Roma, 1974, págs. 31 y 61, tipo Xc; pág. 110, lám. XIV, n. ${ }^{\circ}$ 160-161 (en oro); págs. 192-193, lám. XXVIII, n. ${ }^{\circ}$ 647-650 (en oro); págs. 196-198, lám. XXX, n. $765-775$ (en plata).

(8) Quillard, B.: Op. cit., págs. 81-86.

(9) Ibidem, págs. 18-19, nota 69 . 
Igualmente, estos colgantes se documentan en el pecho de las figuras femeninas de terracota, tanto en Cartago (figura alada de Sainte Monique que lo lleva colocado en sentido invertido y carente de umbo y sistema de suspensión), como en Ibiza (necrópolis del Puig des Molins y santuario de la Cova des Cuieram); todos estos ejemplares de la diosa Tanit están fechados en los siglos IV - III a. C. (10).

Este tipo de colgante es de origen oriental y sería una derivación del fruto de la mandrágora, planta mediterránea con propiedades mágicas, y, por consiguiente, con cierto valor de amuleto. Lo encontramos en Egipto desde el Imperio Medio, en los collares ousekh que lleva Nefertari (esposa de Ramsés II) en una pintura de la cámara funeraria, y dos estatuas masculinas de piedra de Golgoi (Chipre), ejemplares todos ellos invertidos y carentes de umbo y sistema de suspensión (11).

El sistema de suspensión en forma de carrete es característico del mundo feniciopúnico, encontrándose en piezas de factura bastante cuidada de los siglos VII-VI a. C. en el Mediterráneo Occidental (12).

Sin embargo, nuestro ejemplar ebusitano, que constituye el primer testimonio real de la presencia de este tipo de joyas en Ibiza (13), no tiene el mismo nivel artístico que caracteriza a algunos ejemplares sardos, cuyos motivos decorativos van acompañados de un finísimo granulado que realza el acabado de las piezas, siendo más semejante a los colgantes de Cartago.

En cuanto a su cronología, se podría encuadrar, al igual que los ejemplares cartagineses, en el siglo VI o incluso, a finales del VII a. C., aunque el modelo, con algunas variantes, perdure hasta los siglos IV-III a. C., como demuestran las terracotas halladas en la isla y en Cartago.

2. ${ }^{\circ}$ Sin $\mathrm{N}^{\circ}$ de inventario (fig. 2).

Colgante en forma de semicírculo alargado, cerrado en su base; su contorno está rematado por un ribete semicircular liso; la parte posterior es lisa. Sistema de suspensión en forma de carrete estriado.

Alt. 1,7 cm.; anchura máxima: $1,2 \mathrm{~cm}$.; grosor máx.: 0,1 cm.; peso: $1,220 \mathrm{~g}$.

Buen estado de conservación (14).

Circunstancias del descubrimiento. Fue hallado en la incineración n..$^{\circ} 25$, situada en la concavidad natural de la roca, retocada parcialmente para darle forma circular, por B. Costa en 1985, en el Solar de Can Petit del Puig des Molins (Vía Romana, 38), al Norte del camino viejo de Sant Josep. Constituía, junto con un fragmento de clavo de bronce, el único ajuar. La sepultura se hallaba, al parecer, intacta.

(10) San Nicolás Pedraz, M. P.: La indumentaria representada en las terracotas de Ibiza, $A E s p A 57$, 1984, fig. 4 , tabla IV, n. ${ }^{\circ}$ A. 6.c. y B. 4.

(11) Veánse todos los ejemplares supra nota 8.

(12) Quillard, B.: Op. cit., págs. 55-80, láms. XXII-XXV; págs. 93-95, lám. XXVIII; Corzo, R.: Cádiz y la Arqueología fenicia, Anales de la Real Academia de Bellas Artes de Cádiz, n. ${ }^{\circ} 1$, 1983, págs. 23-24, lám. 4 (abajo); Perea, A.: La orfebrería púnica de Cádiz, Aula Orientalis 3, 1985, p. 300, grupo VI, subgrupo C.

(13) Se desconoce a qué pieza de estas características se refieren Schubart y Mass como procedente del Puig des Molins cuando estudian el ejemplar hallado en la necrópolis de Jardín; $c f$. Jardín: informe preliminar sobre las excavaciones de 1974, NAH 6, 1979, págs. 146-147, lám. Xb.

(14) Ha sido tratado en el Museo de Ibiza. 

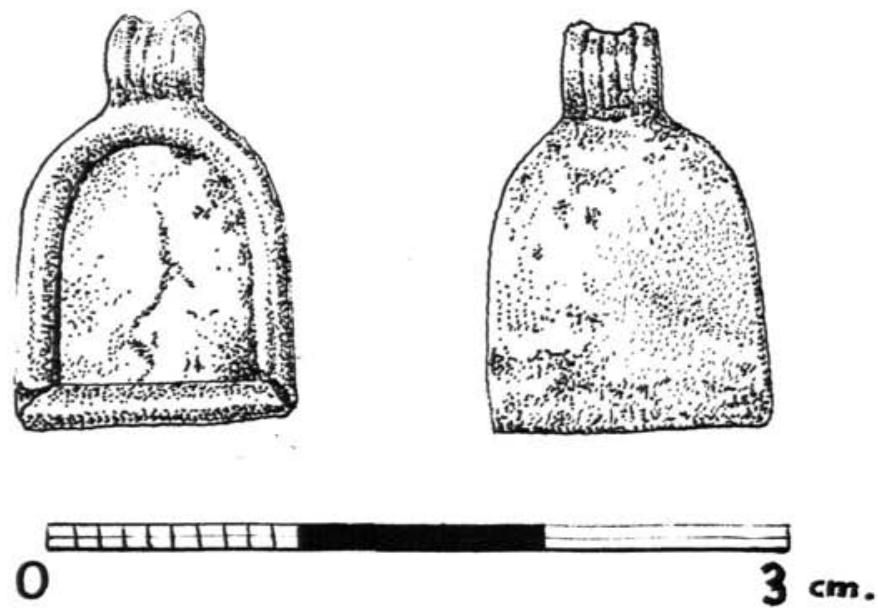

Paralelos. Este colgante pertenece al tipo XI de Quattrocchi (15) y a los «colgantes en forma de nicho" de Quillard (16), hallados en Cerdeña, Sicilia, Cartago y Argelia. La mayoría de estos ejemplares presenta, por medio de un finísimo granulado o repujado aplicado, motivos decorativos orientales: disco alado, uraei, sacrum (en signo de "botella") mesas o altares de sacrificio con moldura egipcia; o geométricos: rombos, triángulos. Dentro de este grupo de colgantes, también existen otros, frecuentemente de plata, carentes de decoración, semejantes a nuestro ejemplar. Todas estas piezas de orfebrería están situadas cronológicamente a finales del siglo VII y primera mitad del VI a. C., fecha en que posiblemente debemos situar el colgante ebusitano.

La forma de estos colgantes recuerda a un nicho o a una estela en miniatura, de base rectangular y coronamiento semicircular. Aunque esta forma suele ser rara en la orfebrería antigua, la encontramos a partir del III milenio a. C., en algunos ejemplares de Ur, Faras (Nubia) y Atlit, éstos últimos de datación incierta, así como en algunos amuletos o tabletas egipcias (17).

La iconografía de algunos de los motivos decorativos, como bien señala Quillard, son semejantes a los de las estelas de Cartago, Motya, Nora... y parecen revelarnos aspectos de un ritual. Este es el caso del discutido signo "de botella" que aparece en la mayoría de los ejemplares como figura central, y que algunos autores han querido poner en relación con el sacrificio de niños pasados por el fuego (vaso - urna, niño + vaso, niño heroizado) o como símbolo de divinidad (ídolo - placa,

(15) Quattrocchi Pisano, G.: Op. cit., págs. 31 y 61, tipo XI; págs. 110-111, lám. XIV, n. 162 (en oro); págs. 168-9, lám. XXIV, n. ${ }^{\circ}$ 411-16 (en plata).

(16) Quillard, B.: Op. cit., págs. 55-66, láms. XXII y XXIII.

(17) Ibidem, pág. 64, notas 317-321. 
betilo). Este holocausto está testimoniado con gran número de establecimientos fenicio-púnicos del Norte de Africa y de las islas del Mediterráneo central, aunque desconocido en la Península Ibérica e Ibiza. No obstante, aunque hoy por hoy desconocemos el verdadero significado y valor religioso de estas piezas, es claro que están relacionadas con la idea de la Muerte-Vida, ya sea propiamente por su forma (nicho o estela), cuanto por la iconografía de sus motivos decorativos.

En suma, estos dos colgantes del Puig des Molins, únicos en sus series, corresponden, dentro de los ejemplares de orfebrería (18), a la fase de fundación de la colonia de Ibiza (654 a. C.), y reflejan una identidad cultural con la ciudad de Cartago. Tanto estos colgantes como otra serie de vestigios, aunque aún no muy numerosos (19), demuestran la utilización de la necrópolis durante la época arcaica.

(18) San Nicolás Pedraz, M. P.: Orfebrería púnica: los collares de Ibiza en el Museo Arqueológico Nacional de Madrid, Saguntum 20, 1986 (en prensa).

(19) Fernández, J. H.: Necrópolis del Puig des Molins (Ibiza): nuevas perspectivas, Aula Orientalis III, 1985, págs. $170-175$. 